\title{
The importance of hydrological uncertainty assessment methods in climate change impact studies
}

\author{
M. Honti ${ }^{1,2}$, A. Scheidegger ${ }^{1}$, and C. Stamm ${ }^{1}$ \\ ${ }^{1}$ Eawag: Swiss Federal Institute of Aquatic Sciences and Technology, Überlandstrasse 133, Dübendorf, 8600, Switzerland \\ ${ }^{2}$ Water Research Group of the Hungarian Academy of Sciences, Múegyetem rkp. 3., Budapest, 1111, Hungary \\ Correspondence to: M. Honti (honti@vit.bme.hu)
}

Received: 22 November 2013 - Published in Hydrol. Earth Syst. Sci. Discuss.: 14 January 2014

Revised: 26 June 2014 - Accepted: 15 July 2014 - Published: 29 August 2014

\begin{abstract}
Climate change impact assessments have become more and more popular in hydrology since the middle 1980s with a recent boost after the publication of the IPCC AR4 report. From hundreds of impact studies a quasi-standard methodology has emerged, to a large extent shaped by the growing public demand for predicting how water resources management or flood protection should change in the coming decades. The "standard" workflow relies on a model cascade from global circulation model (GCM) predictions for selected IPCC scenarios to future catchment hydrology. Uncertainty is present at each level and propagates through the model cascade. There is an emerging consensus between many studies on the relative importance of the different uncertainty sources. The prevailing perception is that GCM uncertainty dominates hydrological impact studies. Our hypothesis was that the relative importance of climatic and hydrologic uncertainty is (among other factors) heavily influenced by the uncertainty assessment method. To test this we carried out a climate change impact assessment and estimated the relative importance of the uncertainty sources. The study was performed on two small catchments in the Swiss Plateau with a lumped conceptual rainfall runoff model. In the climatic part we applied the standard ensemble approach to quantify uncertainty but in hydrology we used formal Bayesian uncertainty assessment with two different likelihood functions. One was a time series error model that was able to deal with the complicated statistical properties of hydrological model residuals. The second was an approximate likelihood function for the flow quantiles. The results showed that the expected climatic impact on flow quantiles was small compared to prediction uncertainty. The choice of uncertainty assessment method actually determined what sources
\end{abstract}

of uncertainty could be identified at all. This demonstrated that one could arrive at rather different conclusions about the causes behind predictive uncertainty for the same hydrological model and calibration data when considering different objective functions for calibration.

\section{Introduction}

Climate change impact assessments have become more and more popular in hydrology since the middle 1980s (Gleick, 1986, 1989; Arnell, 1992) with the recognition that the global climate can be influenced by humankind and that the growing emission of greenhouse gases into the atmosphere has already started a global warming. The topic received another boost when the public perception of climate change transformed after the publication of the IPCC AR4 report (IPCC, 2007) and climate change became a politically and economically accepted boundary condition for the future. From that point onwards no responsible planning could omit the possible effects of an altered climate on water availability, flood levels or other hydrological resources or threats. Hundreds of studies were carried out on almost every significant catchment of the world (for a global summary see Kundzewicz et al., 2007; for a selection of more recent studies see Todd et al., 2010). During this bloom of impact studies a quasi-standard methodology emerged (Blöschl and Montanari, 2010; Todd et al., 2010). The procedure is mostly shaped by the growing public demand for predicting how water resources management or flood protection should change in the near future. Impact studies need to accomplish an apparently impossible task: simulate future relevant 
hydrological events driven by local or extreme meteorological phenomena, which cannot be described by present climatic models. The common procedure is based on a pragmatic approach that "corrects" for the bias in climate model outputs and then drives a calibrated hydrological model with the adjusted weather data (Blöschl and Montanari, 2010; Todd et al., 2010).

The impact predictions are as uncertain as any forecast that tries to describe the behaviour of an extremely complex system decades into the future. First of all, future climate predictions are uncertain due to the intrinsic uncertainty of their inputs: future emission scenarios are represented by a handful of representative story-lines managed by the IPCC, the translation of emissions and projected radiative forcing into actual weather is done by global circulation models (GCMs) that exhibit obvious deficiencies in simulating phenomena on finer resolution than continental scale (Xu, 1999; Blöschl and Montanari, 2010; Ehret et al., 2012) or which according to some metrics do not work at all (Koutsoyiannis et al., 2008; Koutsoyiannis, 2010). Consequently, the GCM-based descriptions of the future climate are preferred to be called as "projections" instead of forecasts due to the immense amount of uncertainty caused by the above described factors (IPCC, 1995). Additionally, there is a non-quantified uncertainty that does not appear in ensembles of emission scenario GCM combinations (Jones, 2000). Like in any hierarchical model system, uncertainty propagates from the climate predictions through the descendant components to regional or local hydrological projections. Downscaling increases uncertainty with the deficiencies of regional circulation models (RCMs) and/or the imperfect stochastic description of the weather by a weather generator (Khan et al., 2006; Kay et al., 2009). Bias correction adds a strong deterministic shift to the input data (Ehret et al., 2012). Finally, the predictive uncertainty of the hydrological model ends the cascade that leads to the total uncertainty of the hydrological impact assessment.

The high uncertainty of the impact of climate change on stream flow is usually admitted, but less often quantified properly. Some studies publish the impacts without any quantification of their uncertainty (Arnell, 2003; Gosain et al., 2006; Thodsen, 2007). Others mostly follow the semiqualitative description of uncertainty throughout the entire model hierarchy by performing ensembles of simulations with different climate and hydrological model components and settings (Boorman and Sefton, 1997; Nijssen et al., 2001; Booij, 2005; Kingston and Taylor, 2010; Gosling et al., 2011; Chen et al., 2011) or focus only on climatic uncertainty and neglect hydrological uncertainty at all (Christensen et al., 2004; Maurer, 2007; Chiew et al., 2009), or even take a single climatic projection and assess only the hydrological uncertainty (Steele-Dunne et al., 2008). Despite the continuous development of quantitative uncertainty assessment methods such as formal Bayesian statistical approaches (Kuczera et al., 2006; Kavetski et al., 2006; Honti et al., 2013) or the
GLUE methodology (Beven and Freer, 2001), these methods are relatively rarely preferred over taking a hydrological model ensemble. There are a few examples of applying GLUE for the estimation of hydrological predictive uncertainty in the context of climate change impact assessment (Cameron, 2006; Wilby, 2005; Wilby and Harris, 2006; Prudhomme and Davies, 2009a; Zambrano-Bigiarini, 2010), but Bayesian uncertainty assessment methods are missing (to our best knowledge).

Despite the diversity in the uncertainty assessment methodology applied in the context of hydrological climate change assessment, there is an emerging consensus between many studies on the relative importance of the different uncertainty sources. The prevailing perception is that GCM uncertainty dominates hydrological impact studies (Wilby and Harris, 2006; Graham et al., 2007; Prudhomme and Davies, 2009b; Kay et al., 2009; Kingston and Taylor, 2010; Arnell, 2011; Hughes et al., 2011; Gosling et al., 2011). There are only a few studies which found that the predictive uncertainty of hydrological models can be in the same range or even larger than climatic uncertainty. This special finding was typically coupled to unusual circumstances: poor hydrologic model performance already in the calibration period (Ludwig et al., 2009), application of an extremely errortolerant equifinality criterion (Zambrano-Bigiarini, 2010) or very different spatial scales treated together during the hydrological modelling (Abbaspour et al., 2009).

However, the universal dominance of climatic uncertainty can be challenged if we consider that the most popular formal and informal likelihood calculation methods in uncertainty analysis (RMSE in GLUE, independent and identically distributed white noise in formal Bayesian calibration) tend to underestimate hydrological predictive uncertainty due to invalid statistical assumptions about the residuals (Schoups and Vrugt, 2010; Reichert and Schuwirth, 2012). Our hypothesis is that the relative importance of climatic and hydrologic uncertainty does not only depend on the hydrological and climate models and the application site, but are also conditional on the uncertainty assessment method.

Our objective is to test the above hypothesis with a climate change impact assessment including statistically sound estimates on the relative importance of the uncertainty sources. The study is performed on two small catchments in the Swiss Plateau with a lumped conceptual rainfall runoff model (CRRM). In the climatic part we apply the standard ensemble approach to quantify uncertainty but in hydrology we use the formal Bayesian uncertainty assessment method with two different likelihood functions. One is a time series error model that is able to deal with the complicated statistical properties of hydrological model residuals (strong heteroscedasticity, autocorrelation, and non-normality). The second is an approximate likelihood function directly for the flow quantiles. The use of this quantile approach is rooted in two observations: first, climate change impact assessment is mostly interested in magnitudes of flow of a given return 
period. The exact timing and hence the time series is not in the focus - the objective functions are statistics on the predicted time series. The second reason for the quantile approach is the fact that uncertainty of these estimates when derived from the time series are not straightforward to quantify properly in a statistical sense. Directed targeting of the objective function of interest may therefore offer advantages that shall be explored in this article.

\section{Methods}

\subsection{Study sites and discharge data}

Our test catchments are the Mönchaltorfer Aa $\left(46 \mathrm{~km}^{2}\right)$ and the Gürbe $\left(137 \mathrm{~km}^{2}\right)$, both lying on the Swiss Plateau on the Northern side of the Alps (Fig. 1). The dominant land-use types are intensive agriculture followed by forests in both sites (57 and $15 \%$ in the Mönchaltorfer Aa, 51 and $21 \%$ in the Gürbe; swisstopo, 2008). Topography is rather different: the altitude difference between the uppermost point and the outflow is moderate for the Mönchaltorfer Aa (440$850 \mathrm{~m}$ a.s.1.), while the highest point in the southern mountainous headwater catchment of the Gürbe is $1650 \mathrm{~m}$ above the river's mouth near Belp (500-2150 m a.s.1.). Soil texture in the Mönchaltorfer Aa catchment is predominantly loamy (BLW, 2008) with cambisols on hillsides and gleysols on flat areas (Wittmer et al., 2010) as major soil types. The lowland area of the Gürbe has similar characteristics, while the alpine part is dominated by coarser, sandy soil material (BLW, 2008).

Discharge is monitored only at a single point along the Mönchaltorfer Aa, close to the outlet (Mönchaltorf) by the Office for Waste, Water, Energy and Air Quality of Kanton Zürich with 10 min frequency (AWEL, 2010). The Gürbe possesses two regular discharge gauges in the main channel operated by the Office of Waste and Water of Kanton Bern (AWA, 2010). One is slightly upstream of the river outlet (Belp), while the other is located about halfway to the headwaters (Burgistein).

\subsection{Climatic input data}

Prediction of daily discharge with reasonable fidelity requires that the input weather data have at least daily resolution as well. Direct RCM output does not cover all necessary parameters for the estimation of potential evapotranspiration (PET) and its precipitation data suffers from severe bias and underestimation of variability. Therefore we applied a stochastic downscaling procedure (weather generation) to produce input for the hydrological model.

\subsubsection{Observed climatic data}

Regular high-resolution meteorological measurements were only available at one off-catchment location for each test catchment. The automatic measurement station of MeteoSchweiz at Wädenswil (10 km SW from Mönchaltorf) was used to drive the model of the Mönchaltorfer Aa, while the station at Bern Zollikofen (10 km N/NE from Belp) was the input for the lower subcatchments of the Gürbe. Additional daily rainfall data from the nearby Blumenstein gauge were used for the uppermost subcatchment of the Gürbe due the significant altitude and climatic difference compared to the lower parts ( 1300 vs. $700 \mathrm{~m}$ a.s.l. average elevation, 1260 vs. $1140 \mathrm{~mm} \mathrm{yr}^{-1}$ in average precipitation).

Daily PET was calculated from radiation and temperature with the simple Hargreaves-Samani method (Hargreaves and Samani, 1982), which was calibrated to match reference crop evapotranspiration given by the full FAO Penman-Monteith equation (Allen et al., 1998).

\subsubsection{Stochastic weather generation}

The EARWIG/UKCP09 statistical weather generator (Kilsby et al., 2007) was trained on the 1981-2010 weather series from Wädenswil and Bern-Zollikofen. This weather generator relies on the Neyman-Scott rectangular pulses (NSRP) model (Rodriguez-Iturbe et al., 1987; Cowpertwait et al., 1996) for the generation of hourly precipitation and simple autoregressive models for the daily values of other weather variables. The NSRP model was trained by optimising the formal statistical properties of the model to match those of the observed data following the procedure described in Fatichi et al. (2011a, b). The autoregressive coefficients were calibrated conditionally on the season (determined by halfmonthly periods) and the transitions between wet (W) and dry (D) days. There were altogether 4+1 transition types: WW, WD, DW, DD (Kilsby et al., 2007) and additionally the DDD type for lasting droughts, which was introduced in the latest version of UKCP09 (Jones et al., 2011).

The difference in weather between the alpine and lowland parts of the Gürbe catchment should have been reflected in the generated weather data too, but the application of a spatial weather generation method like the STNSRP model (Burton et al., 2008) or the NSAR model (Burton et al., 2010) was impossible due to the lack of high-frequency observations for the Blumenstein gauge. To overcome this problem we generated the alpine precipitation conditionally on the lowland weather with a black box model (Appendix A).

\subsubsection{Future climatic data}

Climate change was represented by $10 \mathrm{GCM}-\mathrm{RCM}$ model chains from the ENSEMBLES project database (http://www. ensembles-eu.org) featuring four GCMs (including HadCM3 with two different sensitivities) and eight RCMs, all run transiently on the IPCC A1B emission scenario (Table SM-5 in the Supplement). Despite the transient data, we chose to have two distinct stationary climates, one for the present and one for the future for a better statistical representation of 


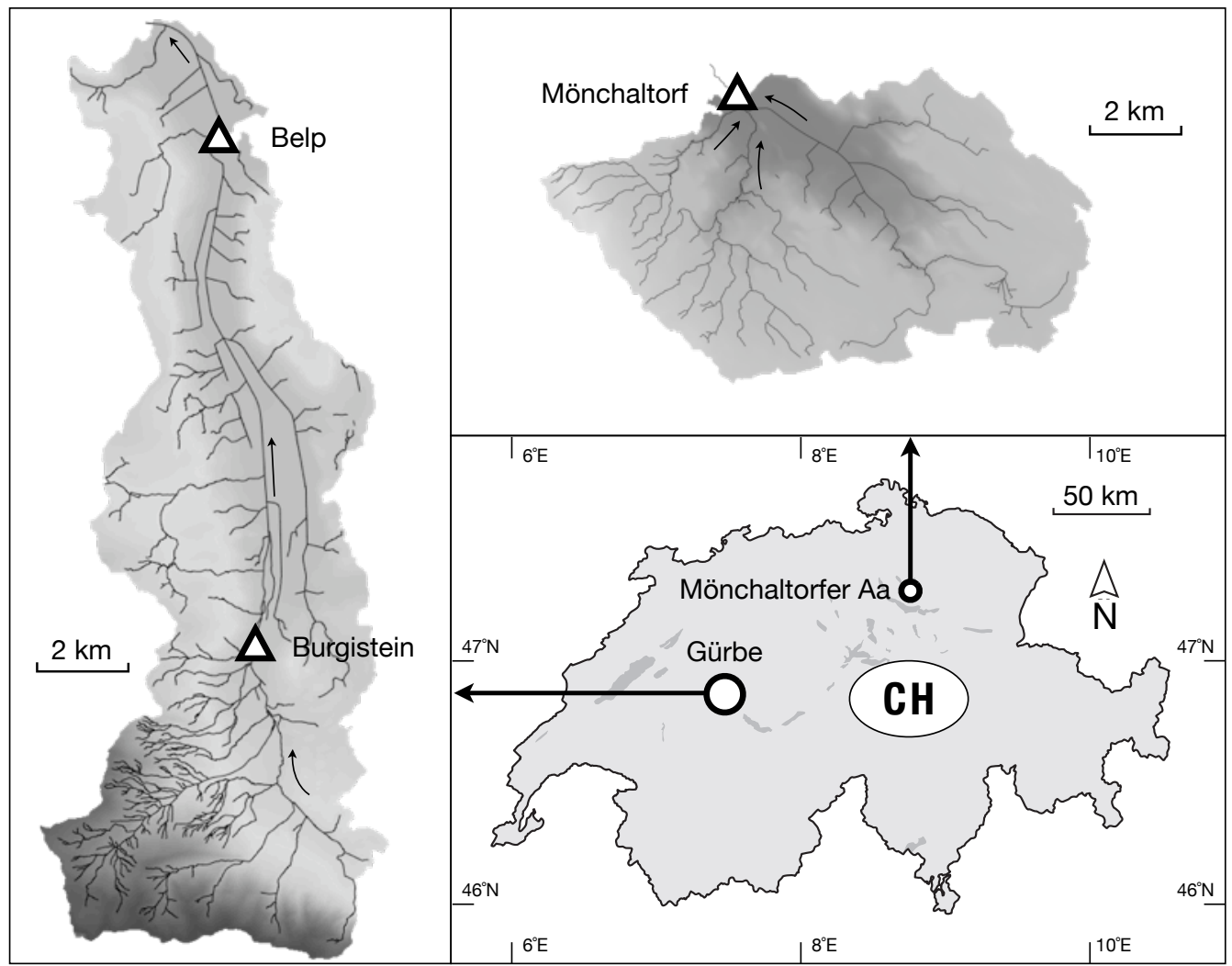

Figure 1. The catchments and gauging sites (triangles) of this study and their locations in Switzerland.

climatic variability. The reference period was 1981-2010, while the forecast period was a 30-year period centred around 2050 (2035-2064). The relatively close forecast time horizon meant that it was sufficient to take a single emission scenario as a representative for all, because the temperature effects of different emission scenarios are still quite similar in this period.

Direct RCM output was not usable for hydrological modelling because both test catchments are situated in the prealpine precipitation gradient zone, which is poorly captured with the coarse spatial resolution of RCMs. This meant that differences between annual precipitation sums from raw RCM data and observations were always significant, for some model chains reaching even $200 \%$. In accordance with common practice, we applied bias correction to the statistics of precipitation and air temperature. The resulting factors of change were introduced to the weather generator following the procedure outlined by Kilsby et al. (2007).

\subsection{Hydrological model}

We used a modified version of the $\log$ SPM model (Kuczera et al., 2006; Honti et al., 2013). LogSPM belongs to the saturated path family of conceptual rainfall-runoff models, in which the heart of the model is a non-linear function describing the saturated proportion of the catchment area as the
Table 1. Relative changes in flow quantiles* due to climate change with different uncertainty assessment approaches.

\begin{tabular}{|c|c|c|c|c|}
\hline $\begin{array}{l}\text { Flow } \\
\text { index }\end{array}$ & $\mathrm{TS}$ & $\mathrm{K} 1$ & $\mathrm{~K} 2$ & $\begin{array}{r}\text { Sign } \\
\text { consensus }\end{array}$ \\
\hline \multicolumn{5}{|c|}{ Mönchaltorf } \\
\hline Q95 & $+2 \pm 9$ & $-1 \pm 11$ & $-7 \pm 12$ & \\
\hline Q50 & $-4 \pm 8$ & $-7 \pm 10$ & $-7 \pm 9$ & $\sqrt{ }$ \\
\hline Q5 & $-4 \pm 11$ & $-8 \pm 9$ & $-8 \pm 9$ & $\sqrt{ }$ \\
\hline \multicolumn{5}{|l|}{ Belp } \\
\hline Q95 & $-15 \pm 4$ & $-14 \pm 6$ & $-4 \pm 7$ & $\sqrt{ }$ \\
\hline Q50 & $-1 \pm 4$ & $-3 \pm 6$ & $-4 \pm 5$ & $\sqrt{ }$ \\
\hline Q5 & $+5 \pm 3$ & $+5 \pm 5$ & $-5 \pm 3$ & \\
\hline \multicolumn{5}{|c|}{ Burgistein } \\
\hline Q95 & $-15 \pm 4$ & $-9 \pm 38$ & $-4 \pm 45$ & $\sqrt{ }$ \\
\hline Q50 & $-1 \pm 3$ & $-3 \pm 29$ & $-4 \pm 26$ & $\sqrt{ }$ \\
\hline Q5 & $+4 \pm 2$ & $+2 \pm 82$ & $-4 \pm 80$ & \\
\hline
\end{tabular}

function of the mean soil moisture content (Kavetski et al., 2003). Water is routed in the soil storage as either runoff, subsurface flow or recharge, proportionally to the saturated area. 
The parameterisation of the saturation function relies on the catchment-scale analogies of characteristic soil moisture contents:

$$
\begin{aligned}
f_{\mathrm{sat}}\left(h_{\mathrm{S}}\right) & =\frac{1}{1+\exp \left(4 \frac{h_{\mathrm{FS}}+h_{\mathrm{FC}}-2 h_{\mathrm{s}}}{h_{\mathrm{FS}}-h_{\mathrm{FC}}}\right)} \\
& -\frac{1}{1+\exp \left(4 \frac{h_{\mathrm{FS}}+h_{\mathrm{FC}}}{h_{\mathrm{FS}}-h_{\mathrm{FC}}}\right)},
\end{aligned}
$$

where $h_{\mathrm{s}}$ is the average soil moisture content of the catchment, $h_{\mathrm{FS}}$ and $h_{\mathrm{FC}}$ are the catchment-scale storage level equivalents of full saturation and field capacity with 98 and $2 \%$ of the catchment area saturated, respectively. Evapotranspiration from the soil moisture storage is controlled in a similar manner to $f_{\text {sat }}$ :

$$
\begin{aligned}
f_{\mathrm{et}}\left(h_{\mathrm{s}}\right) & =\frac{1}{1+\exp \left(8 \frac{3 h_{\mathrm{WP}}+h_{\mathrm{FC}}-h_{\mathrm{s}}}{3 h_{\mathrm{WP}}+h_{\mathrm{FC}}}\right)} \\
& -\frac{1}{1+\exp (8)}
\end{aligned}
$$

where $h_{\text {WP }}$ is the catchment-scale moisture level equivalent of the wilting point (the actual evapotranspiration is only $5 \%$ of the potential). The groundwater and stream storages are simple linear reservoirs. To simulate hydrology under different topographic or land-cover conditions, this basic conceptual model was combined with a snow module based on the degree-day method (Martinec and Rango, 1981), a canopy module based on the interception model of Vrugt et al. (2003) and a simple non-leaking threshold storage for paved areas (Fig. 2). Model equations are presented in Supplement (Table SM-1).

\subsubsection{Spatial discretisation}

The test catchments were spatially discretised using the hydrological response unit (HRU) concept based on land use and soil similarity. The subcatchments of discharge gauging stations were split into "forest", "grassland" (including true grasslands, treeless agricultural areas, non-paved urban zones) and "paved" classes, each represented by a single HRU. Each HRU was assigned a separate soil and canopy unit. Similar HRUs shared a common parameter set. Soil types were assumed to be exclusively from the loamy category on the entire Mönchaltorfer Aa catchment (Frey et al., 2011), while the Gürbe was divided into a lower and upper zone with loamy and sandy soil types, respectively. In the end there were three HRUs in the Mönchaltorfer Aa due to the three distinct land-use types and the lack of a topographic division, while for the Gürbe the separate treatment of the upper and lower zones above the Burgistein gauge and the additional lowland subcatchment between Burgistein and Belp forced the application of nine HRUs in total.

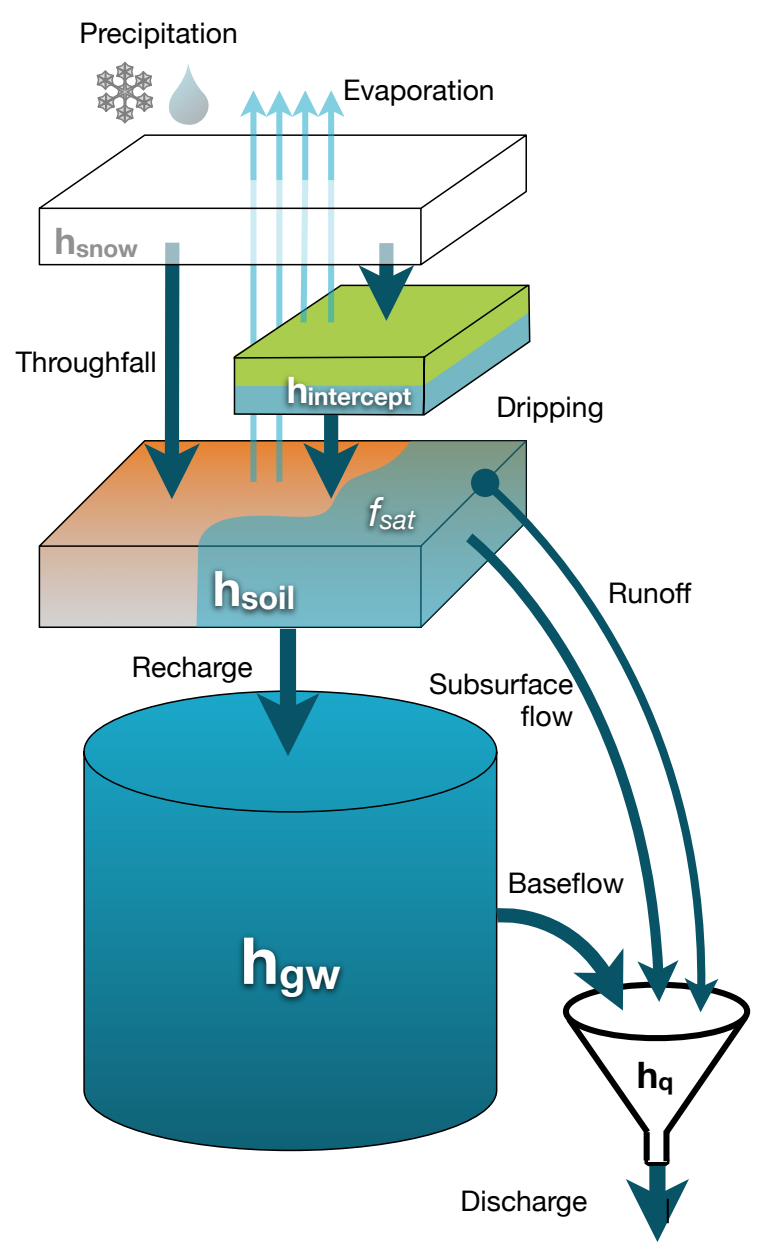

Figure 2. Schematic structure of the applied hydrological model.

\subsubsection{Parameter priors}

Due to the lack of previous conceptual modelling studies in the test catchments we collected prior knowledge about the parameters of the hydrological model by a literature review. Thanks to the reuse of simple and well-known modelling blocks for the snow, canopy and paved module we found several relevant parameter estimates. The prior values for the dripping rate from the canopy storage ( $\left.k_{\text {drip }}\right)$ were so high compared to the daily resolution of the computation that this parameter was fixed to $400\left[\mathrm{~d}^{-1}\right]$ and excluded from the calibration. Priors for the characteristic average soil moisture contents were derived from the water retention curves of the dominant soil types with the van Genuchten model (van Genuchten, 1980) and the default parameters from the ROSETTA program (Schaap et al., 2001) and the assumption of a $1 \mathrm{~m}$ thick active surface layer. Priors for the conceptual catchment parameters $\left(k_{\text {rge }}, k_{\mathrm{bf}}, k_{q}\right.$, etc.) were formulated with subjective estimation on their acceptable domain. All prior distributions are described along with supporting references in the Supplement (Tables SM-2-SM-4). 


\subsubsection{Hydrological indicators}

To facilitate the comparison of observed and predicted hydrological conditions, we rely on a small set of aggregated discharge statistics (namely flow quantiles) similarly to some previous studies (Arnell, 1992; Gosling et al., 2011). We use the 95, 50 and $5 \%$ exceedance quantiles (Q95, Q50 and Q5, respectively) at the discharge gauge sites to represent low, medium and high flow. The selection of these less extreme occurrence probabilities for the assessment ensures that the outcome does not depend heavily on truly extreme events. This is important for two technical reasons. First, the occurrence of extreme precipitation events and consequently extreme floods may be influenced more by internal climatic variability than by climate change itself (Fatichi et al., 2013). However, we describe this only to a very limited extent by taking 30 years of data from each model chain, which is inappropriate to represent rare events. Second, extremes are generally poorly simulated by models of both climate and hydrology, so going for extreme flow indicators would further increase predictive uncertainty.

\subsection{Impact and uncertainty assessment}

In this study we distinguish several sources of predictive uncertainty. The total predictive uncertainty in such a climate change impact assessment is the aggregated uncertainty that affects the future discharge predictions from all quantifiable sources. Due to our limited knowledge there is always unquantifiable uncertainty as well, but this is usually outside the scope of statistical uncertainty assessment methods. We distinguish the following uncertainty contributors arising typically from different imperfect models in the impact assessment workflow:

- Hydrological model uncertainty is the uncertainty of discharge predictions that is present when the hydrological model predictions are made based on observed weather data. This uncertainty is quantifiable by comparing model predictions to actual discharge observations. This is a composite effect of input uncertainty (weather observations are not precise), model structural uncertainty (hydrological models are imperfect) and observation uncertainty of the calibration data.

- Climatic uncertainty is again an aggregate uncertainty source. Weather itself has a natural variability that makes hydrologic predictions uncertain even when hydrological model uncertainty would be negligible. GCM and RCM uncertainty has implications for discharge predictions as well. Whenever a statistical downscaling procedure is applied the errors from imperfect weather generators (WGs) distorts weather properties and increases the input uncertainty of the hydrological model.

These uncertainty components accumulate along the impact assessment workflow, but there is no general recipe to disentangle the individual sources from the total uncertainty directly. Therefore we use a sequential analysis of accumulated uncertainty along the workflow. We compare variability and bias in each stage of the workflow to get an overview about the importance of different sources.

The total uncertainty of our hydrological predictions was assessed with a hybrid approach. Similarly to the majority of climate impact studies we also assumed that the $10 \mathrm{GCM}-$ RCM chains properly represent the uncertainty of the modelled future climate. However, contrary to others (Boorman and Sefton, 1997; Booij, 2005; Gosling et al., 2011) we did not apply the same approach to the hydrological side by representing the existing hydrological uncertainty with a set of different model structures or settings: we used a single conceptual model for hydrology with three versions of two Bayesian uncertainty assessment techniques.

\subsubsection{Discharge time series approach (TS)}

The first variant for the hydrological uncertainty analysis relied on the predictive uncertainty of future discharge series. We considered an additive frequentist observation error together with a similarly additive Bayesian bias process that was designed to represent the effects of both model structural deficiencies and input uncertainty (Honti et al., 2013). The predicted future "true" discharge arose from the output of the deterministic CRRM plus the stochastic bias process reflecting epistemic uncertainty (Honti et al., 2013).

A sample of the posterior parameter distribution was generated with Markov chain Monte Carlo sampling (for details see Honti et al., 2013). The posterior sample was used to produce model predictions of discharge and then selected flow quantiles for each stage of the impact assessment workflow (Fig. 3, stage 0 being the observed discharge):

stage 1: prediction based on observed weather data (1981-2010);

stage 2: prediction based on generated weather data that reflect the reference "present" climate (1981-2010);

stage 3: prediction based on generated weather data that represents a stationary future (2035-2064) climate projection by a single GCM-RCM model chain.

Since all GCM-RCM model chains refer to the same future climate that realises under the IPCC A1B emission scenario, the predictions from the different model chains together represent the future climate. We did not differentiate between individual model chains based on their skill or performance as for example Gleckler et al. (2008) did, so the future climate in our assessment was represented with a model chain ensemble with uniform weights. Accordingly, the corresponding flow quantiles could be mixed together to get a sample of the future.

The uncertainty of weather generation and the stochastic downscaling of the future climate was assessed only 
Workflow stages for TS and K1

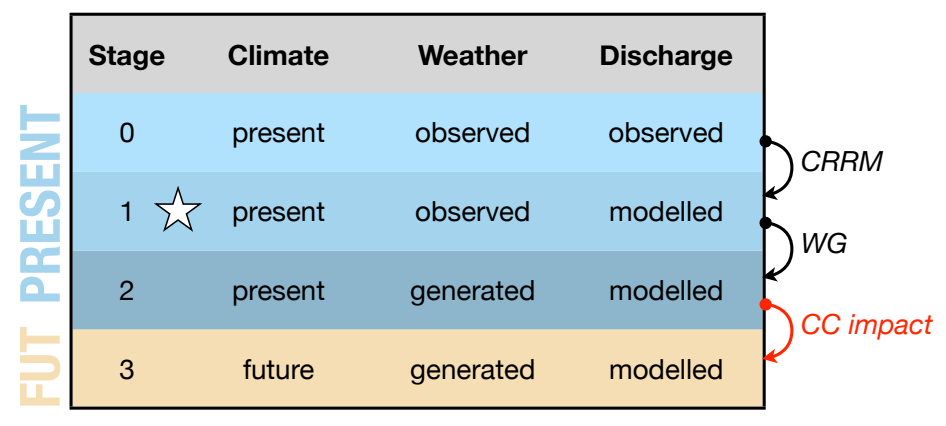

Workflow stages for K2

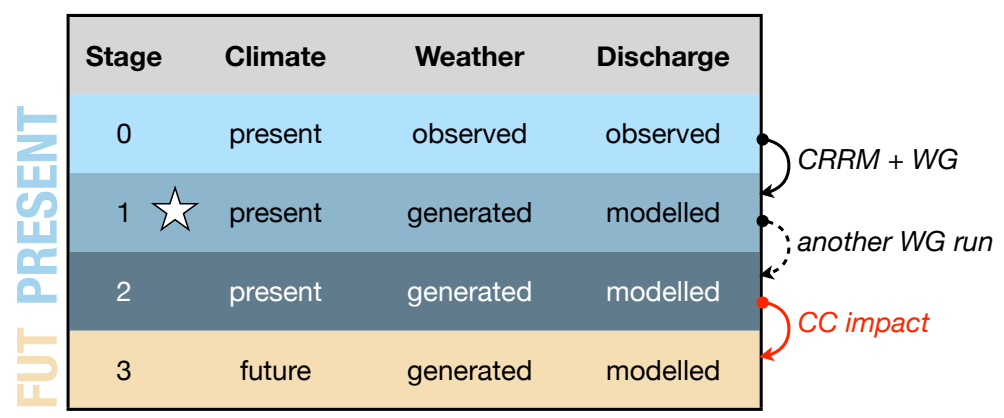

Figure 3. Scheme of workflow stages for different uncertainty assessment approaches. White stars indicate the stages where the parameters of the hydrological model were calibrated. "Climate" specifies the distribution of climatic parameters ("present"/"future") and "Weather" tells whether the actual weather data are observed or generated. WG: weather generator; CC: climate change.

implicitly. We assumed that the lengths of the baseline and prediction periods (30 years both) with daily resolution are enough to produce a statistically well-defined sample of the target flow quantiles, so we used one realisation of the generated weather for the reference period and one for each model chain prediction.

\subsubsection{Discharge quantile approach $(\mathrm{K})$}

Besides deriving the target flow indicators from the predicted time series we also applied a direct approach. We kept the same CRRM, but performed the calibration and produced the parameter posterior sample based on the approximate likelihood of the quantiles themselves. Under some mild statistical assumptions the likelihood of the quantiles can be approximated by independent normal distributions. The details of the approximate quantile likelihood function are described in Appendix B.

Calibration without time series fitting is already quite common in hydrology. For example, Montanari and Toth (2007) used the spectral properties of the flow time series as a measure of fit. Blazkova and Beven (2009) used certain flow quantiles among several other aggregated measures as acceptability criteria for their GLUE-based approach. Westerberg et al. (2011) performed model calibration based on fitting flow-duration curves with a triangular informal likelihood function. In our case we used a formal statistical approach to essentially the same problem as Westerberg et al. (2011) addressed: using aggregated flow statistics for reference offers interesting possibilities. Flow quantiles are independent of time. This means that timing errors, like slightly early or delayed flood peaks, do not influence the model performance significantly.

We utilised this property in the estimation of climate change impacts. In the first variant (K1) of the quantile approach we went through the same workflow stages as described for the time series approach. However, in the second variant (K2) we merged stages 1 and 2 because we used the observed discharge data and the generated weather for the present together for calibration and the sampling of the parameter posterior (Fig. 3).

\subsection{Comparison of different uncertainty effects}

The relative importance of uncertainty entering different stages of the impact assessment and the effect of climate change itself was compared with a simple approach. The change in the flow index distribution between the observed uncertainty of the flow quantiles and stage 1 corresponds to the effect of hydrologic modelling in TS and K1 and to the composite effect of hydrological modelling and weather generation in K2. Similarly, transition between stages 1 and 2 


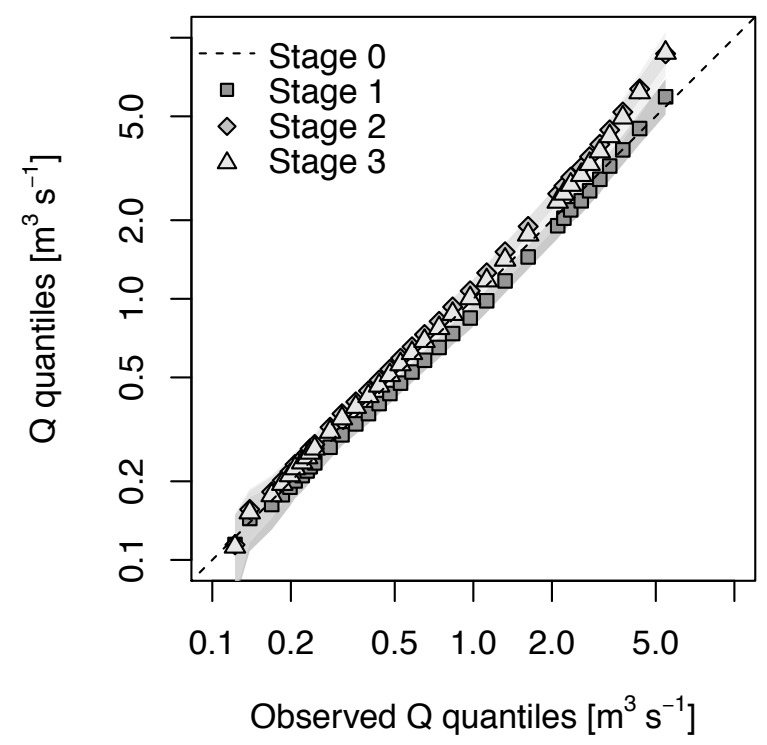

Figure 4. Modelled flow plotted against the observations in different workflow stages (Mönchaltorf, TS approach).

reflects the effect of using generated weather data instead of the observations in $\mathrm{K} 1$ and the effect of the internal variability of weather generation in $\mathrm{K} 2$.

In theory, the flow quantiles in stages $0-2$ should not differ as these all represent the same present hydrology. Accordingly, any change in the distribution of flow quantiles during the transition between these stages can be attributed to existing hydrological and meteorological uncertainty. In contrast, the change in the distribution of flow quantiles between stage 2 and the joint predictions of the future by the 10 model chains should reflect the impact and uncertainty of climate change.

\section{Results}

We present the results for the different uncertainty assessment approaches by study site.

\subsection{Mönchaltorfer Aa}

\subsubsection{Time series approach}

In accordance with our expectations, the CRRM performed well in simulating the observed discharge data with TS. The maximum likelihood solution had a Nash-Sutcliffe index (NS) of 0.8. Despite this good model performance, the selected flow quantiles (Q95, Q50 and Q5) showed significant uncertainty already in stages 1 and 2 without the effects of climate change (Fig. 4). Although these stages both should have corresponded to the observed reference meteorological and hydrological conditions, the simulated flow quantiles were biased in each stage and their variability was

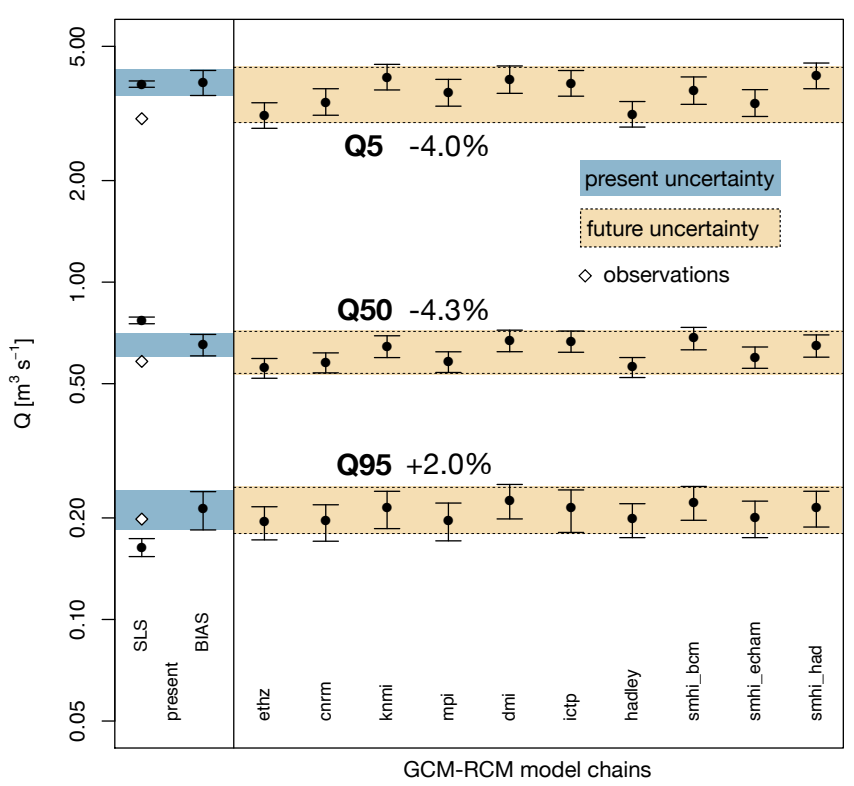

Figure 5. Flow index predictions for Mönchaltorf with the TS approach. Predictions for the present (left side) were made using generated precipitation (stage 2). SLS: simple least squares calibration (for reference), BIAS: the Bayesian error model of TS. The right panel shows future predictions for the individual model chains. Future uncertainty is the joint prediction from all 10 model chains.

significantly larger than that of the observations (Fig. 5). Stage 1 introduced a relative offset between -5 to $-10 \%$ for each quantile, while the $95 \%$ uncertainty interval width was between 10 and $20 \%$ of the observed flow quantiles. Weather generation (stage 2) caused a significant positive offset, which over-compensated for the underestimation in stage 1 .

Since stages 1 and 2 did not produce flow quantiles identical to the observations, the operational definition of the climate change impact matters. Just comparing the observed quantiles with results from stage 3 would yield an increase for all three flow quantiles. However, quantifying the climate change effect as the difference between stages 2 and 3 shows that Q95 was predicted to increase slightly in the future, while Q50 and Q5 were likely to decrease. One had to notice that the expected climate change impact was always much smaller than the offsets caused by the previous stages. The procedure of analysing the difference between stages 2 and 3 essentially meant that we applied a bias correction for the quantile offsets caused by the present uncertainty.

The variability of future flow quantiles was high for each of them (Table 1), compared to the expected climate change impact (Fig. 6). However, the source of this variability differed by flow index: for Q95 it was the modelling uncertainty (stage 1), while for Q50 and Q5 it was the future climate (stage 3 ) which contributed most to the final uncertainty. 


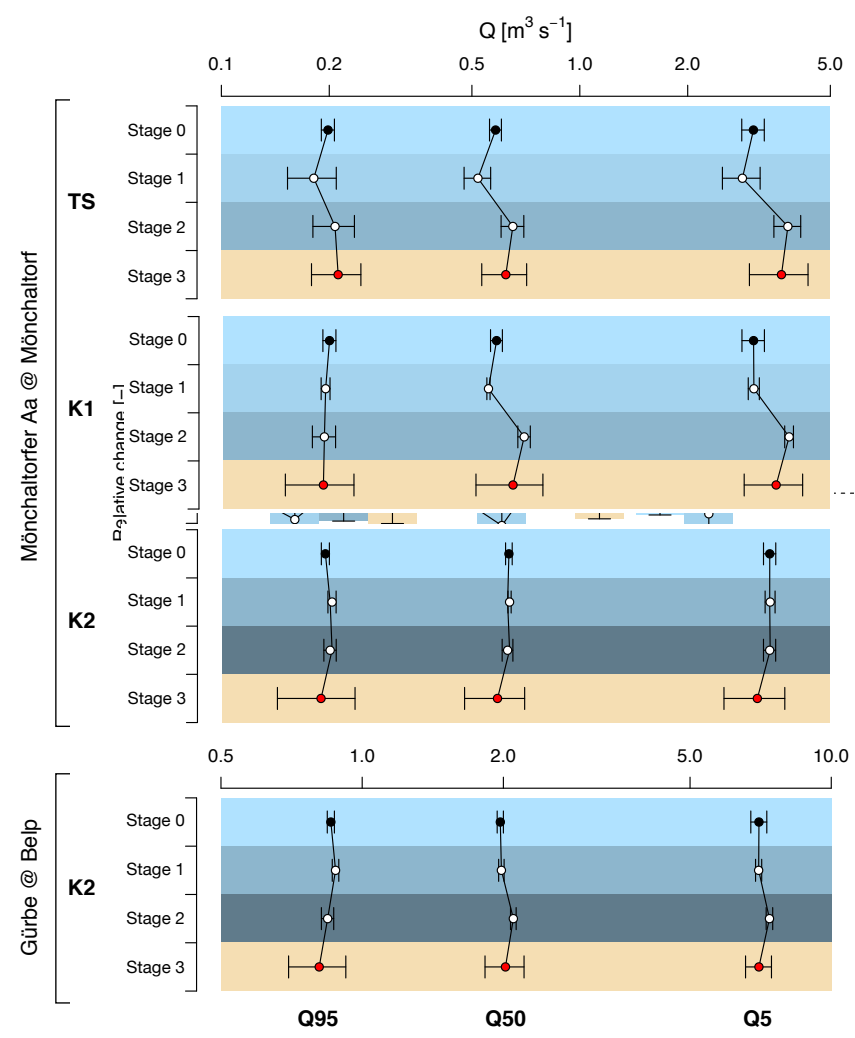

Figure 6. Absolute changes in flow quantiles during different workflow stages.

\subsubsection{Quantile approach}

To our surprise, the calibration to quantiles with observed weather data (K1) also resulted in good agreement between the simulated and the observed flow time series $(\mathrm{NS}=0.75)$ although timing had not been considered in the calibration process. When calibrating with the generated weather series (K2), this performance decreased to $\mathrm{NS}=0.65$ but could still be considered as satisfactory. These good fits demonstrated that the temporal dynamics of discharge were clearly determined by precipitation, so one could predict discharge peaks quite well even without looking at the time series during the calibration of CRRM parameters.

Flow quantiles could be calibrated well to the observed discharge in each version $(\mathrm{K} 1,2)$; quantile offsets were between $1-6 \%$. In $\mathrm{K} 1$, the quantiles still showed significant offsets upon calibration with the generated weather series (stage 2; Fig. 6). The weather generation again caused a positive bias in two flow quantiles (Q50, Q5). This could be completely avoided in $\mathrm{K} 2$. This meant that $\mathrm{K} 2$ resulted in different CRRM parameters to correct for any bias between the original stages 1 and 2 resulting from the interaction between uncertainty of the hydrological model and the weather generator.
Flow quantile variability was dominated by the future climate uncertainty in both versions - variance in stage 3 was much higher than in the previous stage(s). In $\mathrm{K} 1$, weather generation was the most important source of bias (Fig. 6), while this was almost completely eliminated in K2 (Fig. 6).

The expected impact of climate change seemed to be a consistent decrease in all flow quantiles (Table 1). The decrease was between -1 and $-8 \%$ in both versions. Variability was again large compared to the expected change.

\subsection{Gürbe}

\subsubsection{Time series approach}

The performance of the CRRM was different in the Gürbe sites. In Belp, model performance was almost as good as in Mönchaltorf. However, the upper subcatchment above Burgistein had diverse problems. The complexity of alpine hydrology could not be completely captured by the simple CRRM despite the dedicated parameter set for the uppermost model unit. This caused a huge negative bias for Q95 at Burgistein, already in stage 1. Q50 was nicely reproduced, but Q5 was underestimated again. Although the most complex weather generation procedure was applied for the Gürbe catchment, stage 2 dominated the quantile offsets. For variability the picture was different - the major source was the future climate uncertainty at both sites and for all quantiles.

The expected impact of climate change was a larger and a subtle decrease for Q95 and Q50, respectively, while Q5 was predicted to increase by $4-5 \%$ at both gauging stations (Table 1). The relative uncertainty of these predictions varied between $2-4 \%$ of the observed flow quantiles, which surprisingly suggests a stronger confidence despite the inferior CRRM performance (Table 1).

\subsubsection{Quantile approach}

With the K1 approach, the observed flow quantiles were almost perfectly matched for the Belp data, while Q50 and Q5 were overestimated by about $20 \%$ in Burgistein. Weather generation (stage 2) meant a negative offset for each quantile at both gauging stations. The expected impact of climate change was quite similar to those from TS: Q95 and Q50 should decrease by 3 to $14 \%$, Q5 should increase by $2-5 \%$ (Table 1). In contrast to TS, the variability of flow quantiles was much higher for Burgistein (Table 1). The poor performance of the CRRM for the alpine subcatchment resulted in high predictive uncertainty (29-82\% standard deviation relative to the observed quantities) for the flow quantiles already at stage 1. This was propagated through the entire workflow, which finally rendered the predictions for this site extremely unreliable (Table 1). As a result, future climate uncertainty could be considered to be responsible for most of the variability at Belp, but the offsets at Belp and the total uncertainty at Burgistein were dominated by the already existing 
uncertainty sources (meteorological and hydrological uncertainty, weather generation uncertainty).

In contrast to the Mönchaltorfer Aa case, the results for the Gürbe catchment with K2 yielded somewhat different climate change impacts compared to K1. Bias removal for stage 2 worked well again (Fig. 6), but the sign of expected change shifted for Q5 in both sites.

The performance difference between Belp and Burgistein and the variable relative importance of uncertainty components seemingly contradicted the fact that Burgistein covered a significant upstream subcatchment of the Belp gauge. Thus the two sites should have reflected comparable characteristics. The explanation for this behaviour is rooted in the different ability of the CRRM to simulate the observed flow time series or quantiles. The inferior performance at Burgistein meant that already the uncertainty at stage 1 was much higher than for the Belp site. This elevated uncertainty was then propagated through the remaining stages of the workflow.

\subsection{Comparison of uncertainty assessment approaches}

The expected hydrological impacts of climate change were similar but not identical with the three uncertainty assessment approaches. The uncertainty of predicted change was always high compared to the mean predicted change, so few percent differences can be regarded as negligible. At the same time, the final uncertainty of the results and the accumulation of uncertainty at the separate workflow stages differed between the approaches. The closest point to a full consensus between the uncertainty assessment approaches was at the single gauging site of the Mönchaltorfer Aa catchment, where the final uncertainty intervals were almost as similar as the expected impacts (Table 1). In the Gürbe catchment, where the performance of the CRRM was worse, the Belp site had less similar uncertainty intervals, but the standard deviations of the results were at least of the same order of magnitude. In Burgistein TS seemed to underestimate the variability of the climate change impact compared to K1 and K2. The poor performance of the CRRM suggests that the Burgistein predictions should have weaker confidence, yet this was only reflected in the results of the quantile approach, but not in TS (Table 1).

\section{Discussion}

\subsection{Relativeness of uncertainty}

Our study found that the applied uncertainty assessment method strongly influenced the degree and source of predictive uncertainty. This was already demonstrated in several other hydrological studies (Pappenberger et al., 2006). However, there is a qualitative difference between formal and informal statistical uncertainty assessment methods with regard to the relativeness of uncertainty. Several studies have shown that many popular informal likelihood functions in
GLUE yield statistically inconsistent uncertainty intervals for hydrological time series (Mantovan and Todini, 2006; Stedinger et al., 2008) and thus the free choice among the diverse informal likelihoods guarantees that the outcome may be statistically wrong in similarly diverse ways. In contrast to this freedom of choice in GLUE, formal methods - including most Bayesian approaches - are based on the principle that statistically valid likelihood functions should be properly representing the (potentially complex) statistical properties of residuals and hence there exists an "absolute" optimal likelihood formulation for each application that achieves the above mentioned goal with minimum statistical complexity. Several attempts have been made to find such formal likelihood functions for hydrological forecasting (Kuczera et al., 2006; Renard et al., 2011; Schoups and Vrugt, 2010; Honti et al., 2013), but so far none of them was able to completely fulfil all requirements. This is in line with Beven's critique on formal methods - that full statistical coherence may be actually impossible to reach and therefore the drawbacks of an informal approach are much less important in practice (Beven et al., 2007).

Here we applied a formal likelihood function for the time series approach and a formal yet approximate likelihood for the quantile approaches. The surprising part of our finding was that one can still get significantly different uncertainty from two formal approaches that each promise to capture the "true" uncertainty. The reasons behind this can be twofold. First of all it is possible that - similarly to informal methods - the applied formal methods are still statistically inconsistent estimators and that is why they delivered such different estimates for the very same total predictive uncertainty. Besides this, a second explanation could be that in the study we actually dealt with two different uncertainties. Based on the demonstrated interaction between stochastic model bias and flow quantiles we believe that time series and quantile uncertainties represent fundamentally different uncertainties - regardless of the assessment methodology - and therefore it is application-specific which can and should be used (see below).

\subsection{Climate change assessment based on quantiles of time series}

Although climate change effects on hydrology are generally assessed by some aggregate statistics, the most common approach is to use a hydrological model calibrated to time series of observed discharge for this purpose instead of calibrating models directly to the aggregated quantities of interest (e.g. flow quantiles). At first glance, this distinction seems unnecessary: if a model describes time series of discharge properly, it is also expected to be a good descriptor of the derived flow quantiles. While this argument holds for a perfect model with no error whatsoever, the situation is more complex if one considers the predictive errors that are always present. The results shown before illustrated that point very clearly. 

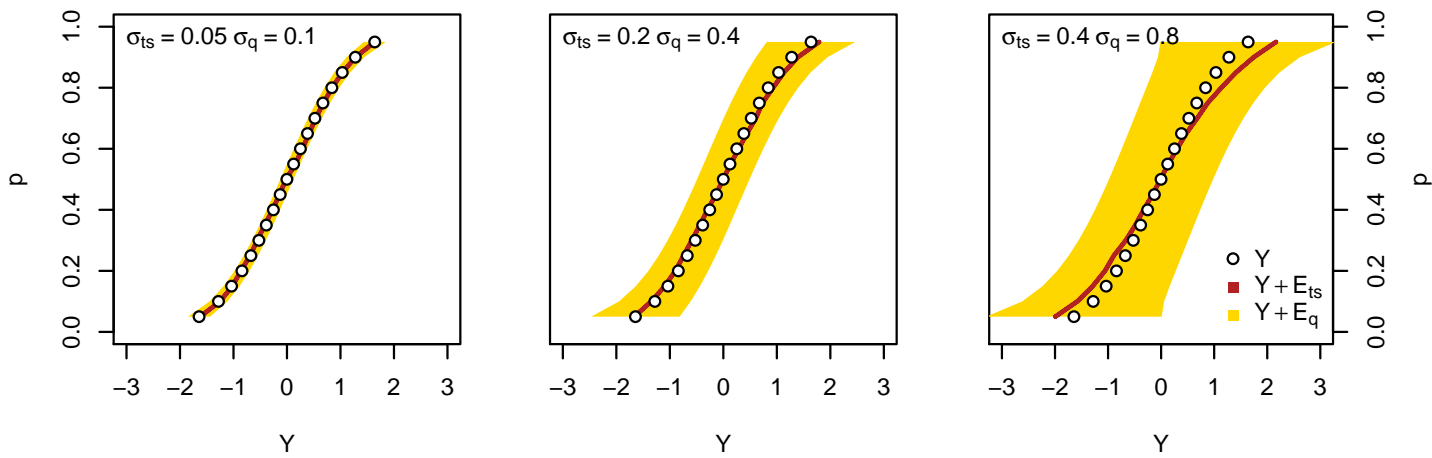

Figure 7. A synthetic example for the different effect of increasing time series and quantile uncertainty on the CDF of $Y+E: Y$ is a standard normal distribution, $E_{\mathrm{ts}}$ is an i.i.d. normal time series error and $E_{\mathrm{q}}$ is a normal quantile error. The uncertainty intervals were derived from 2000 realisations, the time series length was 2000 as well.

An additive stochastic time series error - regardless of whether it is an independent noise or an autoregressive process - automatically increases the variance of the CRRM model output, to which it is added to. Consequently, the simulated flow quantiles will spread outwards (Fig. 7), low flow quantiles will become lower, and high flow quantiles will become higher. This has a profound effect in a time series approach: if we account for the increasing non-observational uncertainty with an autoregressive bias term, it is guaranteed that the predictive flow quantiles will be more extreme there than in the calibration phase. This means that extreme events seem to be more likely due to our weaker knowledge about the future (compared to the past) without any change in the climate or hydrology.

However, while the increase in variance and the corresponding effect on the flow quantiles sounds obvious, it is more difficult to recognise the effect in the study outcome. Quantiles get biased due to the error addition, but at the same time their variance does not increase so much that their uncertainty interval would still encompass the original value. As a result the analyst must face some strongly biased but seemingly confident estimations on altered flow quantiles purely because of existing uncertainty.

The inevitability of biased quantiles in TS suggests that based on the change in flow quantiles alone one cannot unambiguously distinguish between the true impacts of climate change and uncertainty propagation in this approach - unless predictive uncertainty was negligible.

\subsection{Interpretation of uncertain flow quantiles in $\mathrm{K} 1$ and K2}

Quantile approaches could circumvent these inherent problems of the TS procedure. The elimination of the significant quantile bias of the additive time series error models is a true improvement over TS. Furthermore, K2 corrects for the bias introduced by weather generation too. Boorman and Sefton (1997) list studies that used flow quantiles to derive the impact of climate change. Q95 was often used to describe low flow (Arnell, 1992; Wilby et al., 1994; Arnell and Reynard, 1996). Q5 was later also used to characterise flood levels (Gosling et al., 2011). We followed along these lines by implementing the two quantile approaches $\mathrm{K} 1$ and $\mathrm{K} 2$.

However, the use of a quantile approach also comes at some costs. The approximate likelihood applied in K1 and $\mathrm{K} 2$ does not explicitly make any assumptions about the sources and properties of uncertainty, so in this regard it is fundamentally different from the error model applied in TS. The use and definition of quantile uncertainty implies several limitations on the interpretation of results:

- Even if we used the same CRRM as for TS, in K1 and $\mathrm{K} 2$ the flow time series are only intermediate products necessary to calculate the flow quantiles. Due to the possibly huge timing errors they cannot be used to derive any additional indicators that involve timing (for example the distribution of the length of baseflow periods). The quantile calculation procedure can be considered as an additional abstraction layer between the CRRM and the likelihood calculation, which renders the entire CRRM and its parameters somewhat more empirical.

- In K1 and K2 we do not know what mechanisms stand behind the uncertainty of flow quantiles. In contrast to this, TS defined observation, structural and input-related uncertainty and the posterior parameters of the error model could be used to specify the relative importance of these sources.

- With the simple definition of quantile uncertainty we assume that the uncertainty generation mechanisms are the same for the calibration and the predictive period. This conflicts with our intention to calculate the quantiles of the true discharge for the prediction period without the observation error of the past. Nevertheless, the (random) observation uncertainty of (non-extreme) flow quantiles is very low for long discharge time series so 
this theoretical limitation usually would not cause any practical problem.

Considering these pros and cons, the different versions of the quantile approach provide a more empirical but viable alternative for uncertainty assessment in cases when flow quantiles are the only targets of the modelling exercise.

\subsection{General aspects of impact assessment procedures}

The climate change impact assessments procedure as used in this work relies on a complex procedure consisting of different steps as is common in this field (Blöschl and Montanari, 2010; Todd et al., 2010). The current status of our prediction models does not allow for making hydrological predictions in a simple way like feeding GCM output directly into a calibration-free hydrological model (Ehret et al., 2012). Today's climate models are unable to simulate the present and thus the future hydrologic drivers without a significant bias (Xu, 1999) and conceptual rainfall-runoff models usually need a site-specific calibration (Blöschl and Montanari, 2010). All these required steps introduce uncertainty into the overall assessment procedure. In this article, we have tried to directly address some of these sources of uncertainty by either quantifying them explicitly in the TS or by avoiding some of them by directly calibrating the reference state model to the quantities of interest (i.e. flow statistics instead of time series).

Despite this explicit treatment of sources of uncertainty one has to consider that there remain several decisive pragmatic assumptions that could not be avoided:

- with the bias correction of GCM or RCM outputs we assume that the bias of the climatic model will stay invariant regardless the climatic change;

- the involvement of downscaling methods assumes that despite the inability of present climatic models to simulate small-scale and dynamic features of the weather we trust that the relationships between local-scale phenomena and regional aggregated weather patterns will be the same in the future;

- the application of calibrated rainfall-runoff models relies on the temporal and climatic invariance of hydrologic model parameters, including their covariance structure.

Each of these assumptions have been refuted at least once based on scientific reasoning or evidence. Bias correction of climate model outputs ruins the physical consistency of climate models and can introduce arbitrary but significant changes into the meteorological forcing (Ehret et al., 2012). Downscaling is usually used to produce localised and often high-resolution precipitation series that ought to drive the rainfall runoff models, but it can be simply considered as a rather speculative extrapolation that relies on the present extreme statistics and the biased, large-scale precipitation output of GCMs or RCMs (Blöschl and Montanari, 2010). Despite their definition, rainfall-runoff model parameters tend to vary in the very same catchment with time (Reichert and Mieleitner, 2009), season (Yang et al., 2007), climate (Merz et al., 2011) or just the internal state of the catchment (Romanowicz et al., 2006).

These problems together make the standard climate impact assessment error prone and increase the uncertainty of results beyond what we have presented above. However, these errors typically result in a biased prediction instead of higher predictive variability, and thus are difficult to identify. Some of these pitfalls can be avoided by carrying out a step-by-step procedure as presented above (bias introduced by hydrological models and weather generation), but some major uncertainty sources will still remain outside the scope of hydrological impact assessment studies (bias of GCMs and RCMs).

\section{Conclusions}

Our study has revealed that the naïve comparison of today's observed flow quantiles to modelled flow quantiles under climate change with calibration to historic discharge time series may lead to erroneous conclusions about the effects of climate change. The uncertainties that go with the different steps of the assessment procedure cause a divergence of the flow quantiles and may also introduce bias that is independent of any climate change effects. Hence, it is crucially important to make sure that effects on flow quantiles in a climate change assessment are actually due to the predicted change in climate and not caused by uncertainties related to other aspects of the assessment procedure including the structural uncertainty of the hydrological model itself. Interestingly, this important source of quantile bias was rarely mentioned in similar studies.

When only considering the effects of climate change, i.e. by directly calibrating to flow quantiles with simulated weather data or by only considering the changes in the last step of the TS approach, our results delivered already well known findings with regard to climate change impacts. The average impact signal was found to be very weak compared to the total uncertainty of future discharge predictions in both of our test catchments for all flow quantiles. A change of a few percent was typically coupled with up to a few $10 \%$ of uncertainty, so for most sites and flow quantiles we could not even be sure about the sign of change. Irrespective of uncertainty assessment method and flow quantile, results suggest that in the future flow conditions may develop in quite different directions.

The results presented here showed that calibrating a CRRM to different quantities of interest (e.g. time series of discharge versus flow quantiles) may result in slightly different parameterisations. Although a CRRM may predict 
reasonable discharge series even when only calibrated to flow quantiles where all timing information is lost, the differences in parameterisation may induce relevant biases on the noncalibrated quantities. In a sense, this procedure degraded the hydrological model to a semi-empirical albeit rather complex mathematical function. There was no guarantee that the simulated discharge time series or the model parameters had any connection with the true physical quantities they originally referred to. This also demonstrated that one could arrive at rather different conclusions about the source, structure and composition of predictive uncertainty for the same hydrological model and calibration data when considering different objective functions for calibration.
On one hand this means that we can only make conditional statements about these internal details of uncertainty. On the other hand the robustness of total predictive uncertainty for the Mönchaltorf and Belp sites (where the hydrological model performance was good) indicates that the suitability of different uncertainty assessment procedures for different purposes (TS for timing-sensitive applications, K2 for flow quantiles) can be the major selection criterion between uncertainty assessment methods. 


\section{Appendix A: Conditional precipitation model}

The task was to produce daily precipitation sums for the alpine subcatchment of the Gürbe based on the highfrequency generated weather for the lowland part. We determined the joint probabilities of having a wet/dry day in Blumenstein based on the weather in Belp. The analysis revealed that the elevated annual precipitation amount in the alpine zone comes with more wet days as well (57.7 vs. $47.3 \%$ of days). The conditional prediction routine assumed that these probabilities are influenced mostly by the topographical differences and will remain constant regardless of the future climatic changes. During prediction we first decided about the wetness status of the alpine subcatchment considering the wetness status of the lowland and the given conditional probability.

For days which were wet in both parts of the catchment we applied a standard back-propagation neural network ( $R$ package neuralnet) with five nodes in each of its two hidden layers to predict the daily alpine precipitation from the daily values of precipitation, mean air temperature, mean global radiation, mean vapour pressure and mean wind speed of Belp. The residuals between the predicted and observed precipitation sums at Blumenstein had 0 mean and were closely normally distributed after a Box-Cox power transform with $\lambda=0.5$. So the final prediction method for homogeneously wet days was the application of the black-box model and the addition of a back-transformed normal noise term.

For days which were dry in the lowland but wet in the mountains we have drawn from a $\Gamma$ distribution, which was parameterised based on the historical precipitation data from such days. The choice of the $\Gamma$ distribution was motivated by the fact that this distribution type was used for drawing precipitation intensities in the Neyman-Scott rectangular pulses model which generated the rainfall for the UKCP09 weather generator.

\section{Appendix B: An approximate likelihood function for flow quantiles}

\section{B1 Calculating the approximate likelihood}

We denote the set of observed flow quantiles with $\boldsymbol{q}^{\mathrm{o}}$, with the individual items indexed as $q_{i}^{\mathrm{o}}$. The modelled flow quantiles $(\boldsymbol{q}(\theta))$ depend on the model parameters $(\theta)$ and are extracted from the modelled flow time series. $F(\boldsymbol{y} \mid \theta)$ is the distribution of the modelled discharge given the model parameters $\theta$, and $f(\boldsymbol{y} \mid \theta)$ is the corresponding probability density function.

We assume that the quantiles are subject to an additive error $\boldsymbol{E}$ so that

$\boldsymbol{q}^{\mathrm{o}}=\boldsymbol{q}(\theta)+\boldsymbol{E}$.
If we consider samples from a distribution $\boldsymbol{E}$ is approximately normally distributed with 0 mean and a variance depending on $\alpha$ and $f(\boldsymbol{y} \mid \theta)$ (Sect. 10.10 in Stuart and Ord, 1994):

$\sigma_{\alpha}^{2}=\frac{1}{n} \alpha(1-\alpha) \frac{1}{f\left(q_{\alpha}(\theta)\right)^{2}}$,

where $n$ is the sample size of $\boldsymbol{y}$. The error of this variance estimator is $O\left(\frac{1}{n}\right)$.

This theorem applies to independent samples, $\sigma_{\alpha}^{2}$ is underestimated for an autocorrelated sample. To make the theorem applicable for the quantile likelihood calculation of discharge series we make the following additional assumptions:

1. The correlation length of $\boldsymbol{y}$ is orders of magnitudes shorter than the length of the observation period (few days vs. many years), so $\boldsymbol{q}(\theta)$ can be regarded as a set of quantiles from an independent sample.

2. We replace $n$ with $n^{\star}$ that refers to an effective sample size with $1 \leq n^{\star} \leq n$. The new parameter characterises the quality of fit to the observations. If $n=n^{\star}$ then the uncertainty of the modelled flow quantiles equals to the sampling uncertainty, so the uncertainty added by the model is negligible. If $n^{\star} \ll n$ then $\boldsymbol{E}$ is dominated by model-related uncertainty. The inverse of $n^{\star}$ can be considered as an uncertainty scaling parameter.

The resulting likelihood function is then

$p\left(q_{\alpha}^{\mathrm{o}} \mid \theta\right)=\mathcal{N}\left[\mu=q_{\alpha}(\theta), \sigma_{\alpha}^{2}=\frac{1}{n^{\star}} \alpha(1-\alpha) \frac{1}{f\left(q_{\alpha}(\theta)\right)^{2}}\right]$.

We calculate $f\left(q_{\alpha}(\theta)\right)$ from $\boldsymbol{y}$ with a kernel density estimator. The kernel distribution is normal, the standard deviation of the kernel is set to

$\sigma_{k}=0.79 n^{-0.2}\left(q_{0.25}(\boldsymbol{y} \mid \theta)-q_{0.75}(\boldsymbol{y} \mid \theta)\right)$.

\section{B2 Sampling from the predictive distribution}

A predictive realisation of the flow quantiles can be computed in two steps. First one needs to calculate $\boldsymbol{q}(\theta)$ with the deterministic rainfall-runoff model based on the model parameters and the input series for the prediction period. In the second step we need to draw a realisation from the uncertainty distribution. To do this we need to calculate the probability density function for the modelled flow. Then we draw the predicted observation quantiles with Eq. (B3). 


\section{The Supplement related to this article is available online at doi:10.5194/hess-18-3301-2014-supplement.}

Acknowledgements. The iWaQa project is financed by the Swiss National Science Foundation (National Research Program \#61 on Sustainable Water Management, Grant \#406140-125866) and the Swiss Federal Office for the Environment. The ENSEMBLES data used in this work was funded by the EU FP6 Integrated Project ENSEMBLES (Contract number 505539) whose support is gratefully acknowledged. We are grateful to Simone Fatichi and Pierluigi Calanca for their help with the stochastic downscaling of climatic data.

\section{Edited by: S. Uhlenbrook}

\section{References}

Abbaspour, K., Faramarzi, M., Ghasemi, S., and Yang, H.: Assessing the impact of climate change on water resources in Iran, Water Resour. Res., 45, W10434, doi:10.1029/2008WR007615, 2009.

Allen, R., Pereira, L., Rae, D., and Smith, M.: Crop evapotranspiration: Guidelines for computing crop water requirements, Tech. Rep. Irrigation and drainage paper 56, United Nations Food and Agriculture Organization, Rome, Italy, 1998.

Arnell, N. W.: Factors controlling the effects of climate change on river flow regimes in a humid temperate environment, J. Hydrol., 132, 321-342, 1992.

Arnell, N.: Relative effects of multi-decadal climatic variability and changes in the mean and variability of climate due to global warming: future streamflows in Britain, J. Hydrol., 270, 195213, 2003.

Arnell, N. W.: Uncertainty in the relationship between climate forcing and hydrological response in UK catchments, Hydrol. Earth Syst. Sci., 15, 897-912, doi:10.5194/hess-15-897-2011, 2011.

Arnell, N. and Reynard, N.: The effects of climate change due to global warming on river flows in Great Britain, J. Hydrol., 183, 397-424, 1996.

AWA: Water quantity and quality monitoring database of Canton Bern, Amt für Abfall und Wasser der Baudirektion des Kanton Bern, Switzerland, 2010.

AWEL: Meteorology and Water quantity database of Canton Zürich, Amt für Abfall, Wasser, Energie und Luft der Bau-, Verkehrs- und Energiedirektion des Kanton Zürich, Switzerland, 2010.

Beven, K. and Freer, J.: Equifinality, data assimilation, and uncertainty estimation in mechanistic modelling of complex environmental systems using the GLUE methodology, J. Hydrol., 249, 11-29, 2001.

Beven, K., Smith, P., and Freer, J.: Comment on "Hydrological forecasting uncertainty assessment: Incoherence of the GLUE methodology" by Pietro Mantovan and Ezio Todini, J. Hydrol., 338, 315-318, doi:10.1016/j.jhydrol.2007.02.023, 2007.

Blazkova, S. and Beven, K.: A limits of acceptability approach to model evaluation and uncertainty estimation in flood frequency estimation by continuous simulation: Skalka catchment, Czech Republic, Water Resour. Res., 45, W00B16, doi:10.1029/2007WR006726, 2009.
Blöschl, G. and Montanari, A.: Climate change impacts - throwing the dice?, Hydrol. Processes., 24, 374-381, 2010.

BLW: Soil suitability map (Bodeneignungskarte) of Switzerland, Bundesamt für Landwirtschaft, Switzerland, 2008.

Booij, M.: Impact of climate change on river flooding assessed with different spatial model resolutions, J. Hydrol., 303, 176-198, 2005.

Boorman, D. and Sefton, C.: Recognising the uncertainty in the quantification of the effects of climate change on hydrological response, Clim. Change, 35, 415-434, 1997.

Burton, A., Kilsby, C., Fowler, H., Cowpertwait, P., and O'Connel, P.: RainSim: A spatial-temporal stochastic rainfall modelling system, Environ. Modell. Softw., 23, 1356-1369, doi:10.1016/j.envsoft.2008.04.003, 2008.

Burton, A., Fowler, H., Kilsby, C., and O'Connel, P.: A stochastic model for the spatial-temporal simulation of nonhomogeneous rainfall occurrence and amounts, Water Resour. Res., 46, W11501, doi:10.1029/2009WR008884, 2010.

Cameron, D.: An application of the UKCIP02 climate change scenarios to flood estimation by continuous simulation for a gauged catchment in the northeast of Scotland, UK (with uncertainty), J. Hydrol., 328, 212-226, 2006.

Chen, J., Brissette, F., Poulin, A., and Leconte, R.: Overall uncertainty study of the hydrological impacts of climate change for a Canadian watershed, Water Resour. Res., 47, W12509, doi:10.1029/2011WR010602, 2011.

Chiew, F., Teng, J., Vaze, J., Post, D., Perraud, J., Kirono, D., and Viney, N.: Estimating climate change impact on runoff across southeast Australia: Method, results, and implications of the modeling method, Water Resour. Res., 45, W10414, doi:10.1029/2008WR007338, 2009.

Christensen, N., Wood, A., Voisin, N., Lettenmaier, D., and Palmer, R.: The effects of climate change on the hydrology and water resources of the Colorado River basin, Clim. Change, 62, 337363, 2004.

Cowpertwait, P., O'Connel, P., Metcalfe, A., and Mawdsley, J.: Stochastic point process modeling of rainfall: 1. single site fitting and validation, J. Hydrol., 175, 17-46, 1996.

Ehret, U., Zehe, E., Wulfmeyer, V., Warrach-Sagi, K., and Liebert, J.: HESS Opinions "Should we apply bias correction to global and regional climate model data?", Hydrol. Earth Syst. Sci., 16, 3391-3404, doi:10.5194/hess-16-3391-2012, 2012.

Fatichi, S., Ivanov, V., and Caporali, E.: AWE-GEN: Advanced Weather Generator Technical Reference, version 1.0, Tech. rep., University of Michigan, Ann Arbor, Michigan, USA, available at: http://www-personal.umich.edu/ ivanov/HYDROWIT/ Models_files/AWE_GEN_COMPLETE.zip, 2011a.

Fatichi, S., Ivanov, V., and Caporali, E.: Simulation of future climate scenarios with a weather generator, Adv. Water Resour., 34, 448467, doi:10.1016/j.advwatres.2010.12.013, 2011 b.

Fatichi, S., Ivanov, V., and Caporali, E.: Assessment of a stochastic downscaling methodology in generating an ensemble of hourly future climate time series, Clim. Dynam., 40, 1841-1861, doi:10.1007/s00382-012-1627-2, 2013.

Frey, M. P., Stamm, C., Schneider, M. K., and Reichert, P.: Using discharge data to reduce structural deficits in a hydrological model with Bayesian inference approach and the implications for the prediction of critical source areas, Water Resour. Res., 47, W12529, doi:10.1029/2011WR009993, 2011. 
Gleckler, P., Taylor, K., and Doutriaux, C.: Performance metrics for climate models, J. Geophys. Res., 113, D06104, doi:10.1029/2007JD008972, 2008.

Gleick, P.: Methods for evaluating the regional hydrologic impacts of global climatic changes, J. Hydrol., 88, 97-116, 1986.

Gleick, P.: Climate change, hydrology, and water resources, Rev. Geophys., 27, 329-344, 1989.

Gosain, A., Rao, S., and Basuray, D.: Climate change impact assessment on hydrology of Indian river basins, Current Sci., 90, 346-353, 2006.

Gosling, S. N., Taylor, R. G., Arnell, N. W., and Todd, M. C.: A comparative analysis of projected impacts of climate change on river runoff from global and catchment-scale hydrological models, Hydrol. Earth Syst. Sci., 15, 279-294, doi:10.5194/hess-15279-2011, 2011.

Graham, L., Andreasson, J., and Carlsson, B.: Assessing climate change impacts from an ensemble of regional climate models, model scales and linking methods - a case study on the Lule River basin, Clim. Change, 81, 293-307, 2007.

Hargreaves, G. and Samani, Z.: Reference crop evapotranspiration from temperature, Trans. ASAE, 1, 96-99, 1982.

Honti, M., Stamm, C., and Recihert, P.: Integrated uncertainty assessment of discharge predictions with a statistical error model, Water Resour. Res., 49, 4866-4884, doi:10.1002/wrcr.20374, 2013.

Hughes, D. A., Kingston, D. G., and Todd, M. C.: Uncertainty in water resources availability in the Okavango River basin as a result of climate change, Hydrol. Earth Syst. Sci., 15, 931-941, doi:10.5194/hess-15-931-2011, 2011.

IPCC: IPCC Second Assessment Report: Climate Change 1995 (SAR), Tech. rep., The United Nations Intergovernmental Panel on Climate Change, available at: http: //www.ipcc.ch/pdf/climate-changes-1995/ipcc-2nd-assessment/ 2nd-assessment.pdf, 1995.

IPCC: IPCC Fourth Assessment Report: Climate Change 2007 (AR4), Tech. rep., The United Nations Intergovernmental Panel on Climate Change, available at: http://www.ipcc.ch/pdf/ assessment-report/ar4, 2007.

Jones, P. D., Harpham, C., Goodess, C. M., and Kilsby, C. G.: Perturbing a Weather Generator using change factors derived from Regional Climate Model simulations, Nonlin. Processes Geophys., 18, 503-511, doi:10.5194/npg-18-503-2011, 2011.

Jones, R.: Managing uncertainty in climate change projections issues for impact assessment, Clim. Change, 45, 403-419, 2000.

Kavetski, D., Kuczera, G., and Franks, S. W.: Semidistributed hydrological modeling: A 'saturation path' perspective on TOPMODEL and VIC, Water Resour. Res., 39, 1246-1253, 2003.

Kavetski, D., Kuczera, G., and Franks, S.: Bayesian analysis of input uncertainty in hydrological modeling: 1 . Theory, Water Resour. Res., 42, W03407, doi:10.1029/2005WR004368, 2006.

Kay, A., Davies, H., Bell, V., and Jones, R.: Comparison of uncertainty sources for climate change impacts: flood frequency in England, Clim. Change, 92, 41-63, 2009.

Khan, M., Coulibaly, P., and Dibike, Y.: Uncertainty analysis of statistical downscaling methods, J. Hydrol., 319, 357-382, 2006.
Kilsby, C. G., Jones, P. D., Burton, A., Ford, A. C., Fowler, H. J., Harpham, C., James, P., Smith, A., and Wilby, R. L.: A daily weather generator for use in climate change studies, Environ. Model. Softw., 22, 1705-1719, doi:10.1016/j.envsoft.2007.02.005, 2007.

Kingston, D. G. and Taylor, R. G.: Sources of uncertainty in climate change impacts on river discharge and groundwater in a headwater catchment of the Upper Nile Basin, Uganda, Hydrol. Earth Syst. Sci., 14, 1297-1308, doi:10.5194/hess-14-12972010, 2010.

Koutsoyiannis, D.: HESS Opinions "A random walk on water", Hydrol. Earth Syst. Sci., 14, 585-601, doi:10.5194/hess-14-5852010, 2010.

Koutsoyiannis, D., Efstratiadis, A., Mamassis, N., and Christofides, A.: On the credibility of climate predictions, Hydrol. Sci. J., 53, 671-684, 2008.

Kuczera, G., Kavetski, D., Franks, S., and Thyer, M.: Towards a Bayesian total error analysis of conceptual rainfall-runoff models: Characterising model error using storm-dependent parameters, J. Hydrol., 331, 161-177, 2006.

Kundzewicz, Z., Mata, L., Arnell, N., Döll, P., Kabat, P., Jiménez, B., Miller, K., Oki, T., Shen, Z., and Shiklomanov, I.: Freshwater resources and their management, in: Climate change 2007: Impacts, adaptation and vulnerability. Contribution of Working Group II to the Fourth Assessment Report of the Intergovernmental Panel of Climate Change, edited by: Parry, M., Canziani, O., Palutikof, J., van der Linden, P., and Hanson, C., 173-210, Cambridge University Press, Cambridge, UK, 2007.

Ludwig, R., May, I., Turcotte, R., Vescovi, L., Braun, M., Cyr, J.F., Fortin, L.-G., Chaumont, D., Biner, S., Chartier, I., Caya, D., and Mauser, W.: The role of hydrological model complexity and uncertainty in climate change impact assessment, Adv. Geosci., 21, 63-71, 2009, http://www.adv-geosci.net/21/63/2009/.

Mantovan, P. and Todini, E.: Hydrological forecasting uncertainty assessment: incoherence of the GLUE methodology. J. Hydrol., 330, 368-381, doi:10.1016/j.jhydrol.2006.04.046, 2006.

Martinec, J. and Rango, A.: Areal distribution of snow water equivalent evaluated by snow cover monitoring, Water Resour. Res., 17, 1480-1488, 1981.

Maurer, E.: Uncertainty in hydrologic impacts of climate change in the Sierra Nevada, California, under two emission scenarios, Clim. Change, 82, 309-325, 2007.

Merz, R., Parajka, J., and Blöschl, G.: Time stability of catchment model parameters: Implications for climate impact analyses, Water Resour. Res., 47, W02531, doi:10.1029/2010WR009505, 2011.

Montanari, A. and Toth, E.: Calibration of hydrological models in the spectral domain: An opportunity for scarcely gauged basins?, Water Resour. Res., 43, W05434, doi:10.1029/2006WR005184, 2007.

Nijssen, B., O’Donnell, G., Hamlet, A., and Lettenmaier, D.: Hydrologic sensitivity of global rivers to climate change, Clim. Change, 50, 142-175, 2001.

Pappenberger, F., Harvey, H., Beven, K., Hall, J., and Meadowcroft, I.: Decision tree for choosing an uncertainty analysis methodology: a wiki experiment http://www.floodrisknet.org.uk/ methods, http://www.floodrisk.net, Hydrol. Process., 20, 3793 3798, 2006. 
Prudhomme, C. and Davies, H.: Assessing uncertainties in climate change impact analyses on the river flow regimes in the UK. Part 1: baseline climate, Clim. Change, 93, 177-195, 2009a.

Prudhomme, C. and Davies, H.: Assessing uncertainties in climate change impact analyses on the river flow regimes in the UK. Part 2: future climate, Clim. Change, 93, 197-222, 2009b.

Reichert, P. and Mieleitner, J.: Analyzing input and structural uncertainty of nonlinear dynamic models with stochastic, time-dependent parameters, Water Resour. Res., 45, W10402, doi:10.1029/2009WR007814, 2009.

Reichert, P. and Schuwirth, N.: Linking statistical description of bias to multi-objective model calibration, Water Resour. Res., 48, W09543, doi:10.1029/2011WR011391, 2012.

Renard, B., Kavetski, D., Leblois, E., Thyer, M., Kuczera, G., and Franks, S. W.: Toward a reliable decomposition of predictive uncertainty in hydrological modeling: Characterizing rainfall errors using conditional simulation, Water Resour. Res., 47, W11516, doi:10.1029/2011WR010643, 2011.

Rodriguez-Iturbe, I., Cox, D., and Isham, V.: Some models of rainfall based on stochastic point processes, Proc. Roy. Soc. London Ser. A, 410, 269-288, 1987.

Romanowicz, R., Young, P., and Beven, K.: Data assimilation and adaptive forecasting of water levels in the river Severn catchment, United Kingdom, Water Resour. Res., 42, W06407, doi:10.1029/2005WR004373, 2006.

Schaap, M., Leij, F., and van Genuchten, M.: ROSETTA: a computer program for estimating soil hydraulic parameters with hierarchical pedotransfer functions, J. Hydrol., 251, 163-176, 2001.

Schoups, G. and Vrugt, J. A.: A formal likelihood function for parameter and predictive inference of hydrologic models with correlated, heteroscedastic and non-Gaussian errors, Water Resour. Res., 46, W10531, doi:10.1029/2009WR008933, 2010.

Stedinger, J. R., Vogel, R. M., Lee, S. U., and Batchelder, R.: Appraisal of the generalized likelihood uncertainty estimation (GLUE) method, Water Resour. Res., 44, W00B06, doi:10.1029/2008WR006822, 2008.

Steele-Dunne, S., Lynch, P., McGrath, R., Semmler, T., Wang, S., Hanafin, J., and Nolan, P.: The impacts of climate change on hydrology in Ireland, J. Hydrol., 356, 28-45, 2008.

Stuart, A. and Ord, J.: Kendall's Advanced Theory of Statistics, Vol. 1, Distribution Theory, Wiley, 1994.

swisstopo: Digital land-use map of Switzerland, Bundesamt für Landestopographie, Switzerland, 2008.

Thodsen, H.: The influence of climate change on stream flow in Danish rivers, J. Hydrol., 333, 226-238, 2007.
Todd, M. C., Taylor, R. G., Osborn, T. J., Kingston, D. G., Arnell, N. W., and Gosling, S. N.: Uncertainty in climate change impacts on basin-scale freshwater resources - preface to the special issue: the QUEST-GSI methodology and synthesis of results, Hydrol. Earth Syst. Sci., 15, 1035-1046, doi:10.5194/hess-15-10352011, 2011.

van Genuchten, M.: A closed-form equation for predicting the hydraulic conductivity of unsaturated soils, Soil Sci. Soc. Am. J., 44, 892-898, 1980.

Vrugt, J. A., Dekker, S. C., and Bouten, W.: Identification of rainfall interception model parameters from measurements of throughfall and forest canopy storage, Water Resour. Res., 39, 1251-1260, doi:10.1029/2003WR002013, 2003.

Westerberg, I. K., Guerrero, J.-L., Younger, P. M., Beven, K. J., Seibert, J., Halldin, S., Freer, J. E., and Xu, C.-Y.: Calibration of hydrological models using flow-duration curves, Hydrol. Earth Syst. Sci., 15, 2205-2227, doi:10.5194/hess-15-22052011, 2011.

Wilby, R.: Uncertainty in water resource model parameters used for climate change impact assessment, Hydrol. Process., 19, 32013219, 2005.

Wilby, R. and Harris, I.: A framework for assessing uncertainties in climate change impacts: Low-flow scenarios for the River Thames, UK, Water Resour. Res., 42, W02419, doi:10.1029/2005WR004065, 2006.

Wilby, R., Greenfield, B., and Glenny, C.: A coupled synoptichydrological model for climate change impact assessment, J. Hydrol., 153, 265-290, 1994.

Wittmer, I., Bader, H.-P., Scheidegger, R., Singer, H., Lück, A., Hanke, I., Carlsson, C., and Stamm, C.: Significance of urban and agricultural land use for biocide and pesticide dynamics in surface waters, Water Res., 44, 2850-2862, doi:10.1016/j.watres.2010.01.030, 2010.

Xu, C.-Y.: Climate change and hydrologic models: A review of existing gaps and recent research developments, Water Resour. Manage., 13, 369-382, 1999.

Yang, J., Reichert, P., Abbaspour, K. C., and Yang, H.: Hydrological modelling of the Chaohe Basin in China: Statistical model formulation and Bayesian inference, J. Hydrol., 340, 167-182, 2007.

Zambrano-Bigiarini, M.: On the effects of hydrological uncertainty in assessing the impacts of climate change on water resources, Phd thesis, University of Trento, Italy, available at: http://eprints-phd.biblio.unitn.it/284/1/MZB-PhD_ Thesis-UT-05Ago2010.pdf, 2010. 